\title{
The radiological outcomes of one-stage posterior-only hemivertebra resection and short segmental fusion for lumbosacral hemivertebra: a minimum of 5 years of follow-up
}

\author{
Yu Wang ${ }^{1}$, Zhen Liư', Changzhi Du', Benlong Shi ${ }^{2}$ Xu Sun², Bin Wang ${ }^{1}$, Zezhang Zhu ${ }^{1}$ and Yong Qiu ${ }^{1 *}$
}

\begin{abstract}
Background: Previous studies have reported favorable short-term outcomes after posterior-only hemivertebra resection and short fusion in patients with LSHV. However, there is a paucity of data evaluating the long-term outcomes following this procedure. The aim of the study is to evaluate the radiological outcomes following posterior-only hemivertebra resection and short fusion for the treatment of congenital scoliosis (CS) secondary to lumbosacral hemivertebra (LSHV) with a minimum of a 5-year follow-up.

Methods: A total of 23 patients treated with one-stage posterior-only LSHV resection and short fusion with a minimum of a 5-year follow-up were reviewed. Radiographic parameters including the Cobb angles of the lumbosacral curve and compensatory curve, the upper instrumented vertebra (UIV) tilt, and trunk shift were measured. The complications were recorded accordingly.

Results: The mean duration of follow-up was $88.6 \pm 28.5$ months, and the average age at surgery was $7.8 \pm 3.5$ years. Fusion levels averaged $3.0 \pm 0.7$ segments. The lumbosacral curve was corrected from $30.7 \pm 10.4^{\circ}$ to $6.7 \pm 7.1^{\circ}$ after surgery $(P<0.001), 7.3 \pm 6.1^{\circ} 2$ years after surgery, and $8.1 \pm 7.0^{\circ}$ at the last follow-up. The compensatory curve was spontaneously corrected from $23.7 \pm 9.4^{\circ}$ before surgery to $8.3 \pm 5.2^{\circ}$ after surgery $(P<0.001)$. However, the angle slightly increased to $9.0 \pm 4.8^{\circ} 2$ years after surgery and to $9.6 \pm 6.4^{\circ}$ at the last follow-up. Trunk shift was improved from $27.3 \pm$ $8.6 \mathrm{~mm}$ before surgery to $11.7 \pm 9.4 \mathrm{~mm}$ after surgery, and it decreased to $10.8 \pm 8.2 \mathrm{~mm} 2$ years after surgery and $10.4 \pm$ $8.8 \mathrm{~mm}$ at the last follow-up. One patient experienced transient neurologic deficits after surgery. One patient was observed to have screw loosening at 1-year follow-up and received revision surgery.

Conclusion: One-stage posterior-only hemivertebra resection with short fusion is an effective procedure for LSHV, and the correction can be well maintained during longitudinal follow-up. Great attention should be paid to the restoration of lumbosacral horizontalization.
\end{abstract}

Keywords: Congenital scoliosis, Lumbosacral, Hemivertebra resection, Posterior-only, Instrumentation, Fusion

\footnotetext{
* Correspondence: scoliosis2002@sina.com

${ }^{1}$ Department of Spine Surgery, Nanjing Drum Tower Hospital, Clinical

College of Nanjing Medical University, Zhongshan Road 321, Nanjing 210008,

China

Full list of author information is available at the end of the article
}

(c) The Author(s). 2019 Open Access This article is distributed under the terms of the Creative Commons Attribution 4.0 International License (http://creativecommons.org/licenses/by/4.0/) which permits unrestricted use, distribution, and reproduction in any medium, provided you give appropriate credit to the original author(s) and the source, provide a link to the Creative Commons license, and indicate if changes were made. The Creative Commons Public Domain Dedication waiver (http://creativecommons.org/publicdomain/zero/1.0/) applies to the data made available in this article, unless otherwise stated. 


\section{Introduction}

Congenital scoliosis (CS) secondary to lumbosacral hemivertebra (LSHV) is a complicated spinal deformity in young children and adolescents [1-6]. From an anatomic and biomechanical view, the lumbosacral region serves as a transitional joint between the highly mobile lumbar spine and the immobile sacrum. Therefore, hemivertebra located in this region frequently results in significant coronal decompensation and a long compensatory curve above, which is reported to progress approximately $1^{\circ}$ to $3^{\circ}$ per year if not treated $[1,3,4]$. Because lumbosacral deformity does not respond effectively to bracing, early surgical management is frequently recommended for patients with demonstrated curve progression and coronal imbalance [3].

Previously, LSHV resection with instrumentation and fusion was performed via one-/two-stage combined anterior and posterior approaches [7-11]. However, the combined procedure is aggressive with a longer operating time and more blood loss [7, 12, 13]. With the substantial advances in posterior instrumentation, the posterior-only approach has gradually become preferred $[12,13]$. However, there remains a debate regarding the selection of the most appropriate fusion level for this deformity, particularly in patients with immature skeletons $[3,4,7]$. Recently, short segmental fusion associated with posterior-only hemivertebra resection, due to its minimized side effects in terms of spine growth and mobility, has drawn the attention of spine surgeons $[7,12,13]$.

Zhuang et al. [12] and Li et al. [13] demonstrated good correction of the lumbosacral curve and coronal trunk shift after posterior-only LSHV resection and short segmental fusion. However, both of the aforementioned studies were limited by a relatively short follow-up period; in particular, most of the enrolled patients were very young and far from skeletal maturity [12, 13]. How the compensatory curve and the coronal balance change during long-term follow-up remain unclear. Therefore, the current study was carried out to assess the radiographic outcomes with a minimum of 5 years of followup in LSHV patients who were treated with one-stage posterior-only hemivertebra resection and short segmental fusion and to evaluate the evolution of the compensatory curve and the coronal imbalance during long-term follow-up.

\section{Materials and methods}

This retrospective study was approved by our hospital's institutional review board. CS patients due to LSHV who were treated with hemivertebra excision between March 2003 and May 2013 were retrospectively reviewed. The inclusion criteria for this study were as follows: (1) having undergone one-stage posterior-only hemivertebra resection, (2) having had short segmental fusion ( $\leq 4$ segments), and (3) having been followed up for at least 5 years. The exclusion criteria were those with multiple hemivertebrae, agenesis of the sacrum, history of spinal surgery, or unequal lengths of the lower extremities. Finally, 23 patients were recruited in our study.

\section{Surgical technique}

After general anesthesia, the patient was placed in a prone position on a Jackson table, and a standard midline incision was performed. The posterior elements of the LSHV and the adjacent normal vertebrae that needed to be fused were carefully exposed. The pedicle screws were inserted into the adjacent normal vertebrae using the freehand technique. The posterior elements of the LSHV, including the facet joints, laminae, transverse processes, and posterior parts of the pedicle, were subsequently excised. After that, the lateral cortex of the LSHV was carefully exposed by blunt dissection. To stabilize the spine, a precontoured rod was provisionally screwed on the concave side and left unlocked. Then, the body of the hemivertebra was removed completely, followed by excision of the adjacent discs. Similarly, the contralateral facet and disc were also removed completely to obtain circumferential release. Cancellous bone from the hemivertebra was used for interbody fusion. Then, the convex side was gradually compressed to close the gap completely. In cases where a large gap was left due to the excision of a large hemivertebra, interbody fusion with a cage was used. During the whole procedure, the dural sac and the nerve roots were cautiously protected. The coronal balance and lumbosacral horizontality were checked under fluoroscopy before wound closure. All of the surgeries were performed under the neuromonitoring of sensory evoked potential (SEP) and motor evoked potential (MEP).

\section{Radiographic assessment}

All radiographs were analyzed by two authors and the average values were calculated. Standing erect posteroanterior and lateral radiographs of the whole spine were evaluated before surgery, immediately after surgery, 2 years after surgery, and at the last follow-up. Threedimensional computed tomography $(\mathrm{CT})$ reconstruction was reviewed to identify the location and segmentation of the hemivertebrae preoperatively. Preoperative magnetic resonance imaging (MRI) of the whole spine was used to record the associated intraspinal malformations.

The parameters measured in the coronal plane included the Cobb angles of the lumbosacral and compensatory curves, the upper instrumented vertebra (UIV) tilt and trunk shift. Lumbosacral lordosis, lumbar lordosis, thoracic kyphosis, and the sagittal vertical axis (SVA) were measured in the sagittal plane. Lumbosacral 
scoliosis and lordosis were defined as the angle between the upper endplate of the vertebra above the hemivertebra and that of the sacrum [7]. The UIV tilt was measured as the angle between the superior endplate of the UIV and the horizontal line. Trunk shift was defined as the horizontal distance between the plumb line drawn from the middle of the $\mathrm{C} 7$ body and the central sacral vertical line (CSVL). Lumbar lordosis was measured as the angle between the superior endplate of L1 and the superior endplate of the sacrum. Thoracic kyphosis was defined as the angle between the superior endplate of $\mathrm{T} 5$ and the inferior endplate of T12 (Fig. 1).

\section{Statistical analysis}

All parameters were analyzed with standardized statistical software (SPSS; version 22). Continuous values were described as the mean \pm standard deviation. Parameters at different time periods were compared using the paired Student's $t$ test. Correlation analysis was used to identify the relationships between the decrement of UIV tilt and the improvement in trunk shift preoperatively to postoperatively immediately. A $P$ value $<0.05$ was regarded as statistically significant.

\section{Results \\ Demographics}

There were 14 boys and 9 girls with an average age of $7.8 \pm 3.5$ years (range, 2.5-13.0 years) at surgery. The hemivertebrae were located at L5 in 10 patients, L5-S1 in 11 patients, and L6-S1 in 2 patients. Among all of them, twenty-one (91.3\%) patients were identified with a grade 0 Risser sign and the other $2(8.7 \%)$ had grade 1 at presentation. The mean follow-up time was $88.6 \pm$ 28.5 months (range, 60-156 months). At the last followup, $4(17.4 \%)$ patients showed a grade 0 Risser, $2(8.7 \%)$ were grade $1,3(13.0 \%)$ were grade 4 , and $14(60.9 \%)$ were grade 5 .

Of the 23 patients, 11 patients were identified to have fully segmented hemivertebrae and 12 with semisegmented hemivertebrae. The fusion span averaged $3.0 \pm 0.7$ levels (range, 2-4 levels), including 6 patients with 2 levels, 12 with 3 levels, and 5 with 4 levels. Interbody cage fusion was performed in 2 patients. The mean

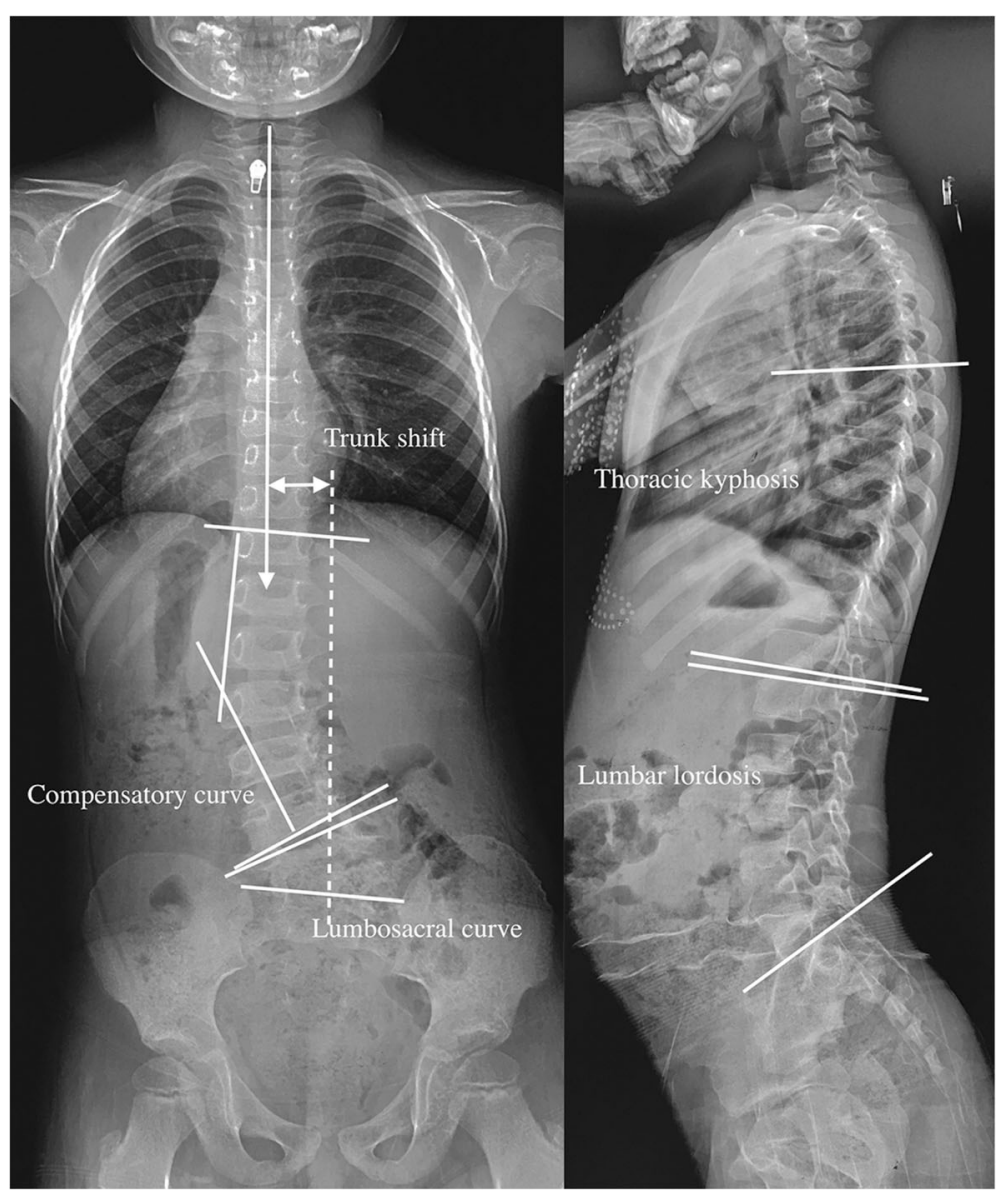

Fig. 1 The coronal and sagittal parameters measured on standing whole spine X-rays 
operation time was $196.7 \pm 13.2$ min (range, 175$230 \mathrm{~min}$ ), and the average amount of blood loss was $271.7 \pm 32.3 \mathrm{ml}$ (range, $200-320 \mathrm{ml}$ ). One patient was identified with tethered cord and syringomyelia (Table 1).

\section{Correction results}

The lumbosacral curve averaged $30.7 \pm 10.4^{\circ}$ before surgery, $6.7 \pm 7.1^{\circ}(79.1 \%$ correction, $P<0.001)$ immediately after surgery, $7.3 \pm 6.1^{\circ}$ (76.9\% correction) 2 years after surgery, and $8.1 \pm 7.0^{\circ}$ (73.3\% correction) at the last follow-up. The UIV tilt significantly improved from $15.3 \pm 6.4^{\circ}$ before surgery to $3.8 \pm 4.3^{\circ}(P<0.001)$ immediately after surgery, $4.0 \pm 5.5^{\circ} 2$ years after surgery, and $4.6 \pm 6.7^{\circ}$ at the last follow-up. Accordingly, trunk shift was significantly improved from $27.3 \pm 8.6 \mathrm{~mm}$ preoperatively to $11.7 \pm 9.4 \mathrm{~mm}$ immediately postoperatively, $10.8 \pm 8.2 \mathrm{~mm} 2$ years postoperation, and $10.4 \pm$ $8.8 \mathrm{~mm}$ at the last follow-up (Table 2, Fig. 2).
Interestingly, the decrease in trunk shift was significantly correlated with the change in the UIV tilt $(r=0.615, P=$ 0.002).

The Cobb angle of the proximal compensatory curve was spontaneously corrected from $23.7 \pm 9.4^{\circ}$ before surgery to $8.3 \pm 5.2^{\circ}$ immediately after surgery, with an average correction rate of $64.2 \pm 21.3 \%(P<0.001)$. However, the angle slightly increased to $9.0 \pm 4.8^{\circ} 2$ years after surgery and to $9.6 \pm 6.4^{\circ}$ at the last follow-up, although the difference was not significant. Progression (more than $5^{\circ}$ ) of the compensatory curve was observed in three patients. Brace treatment was prescribed, and no additional surgery was required due to compensatory curve progression at the last follow-up.

\section{Complications}

Transient neurologic complications were observed in one patient. After 3 months of conservative treatment, this patient recovered completely. No infection,

Table 1 Demographic, anatomic and operative data of the 23 resected hemivertebrae

\begin{tabular}{|c|c|c|c|c|c|c|c|c|c|c|c|c|c|}
\hline $\begin{array}{l}\text { Patient } \\
\text { no. }\end{array}$ & Sex & $\begin{array}{l}\text { Age at } \\
\text { surgery } \\
\text { (years) }\end{array}$ & $\begin{array}{l}\text { Location of } \\
\text { hemivertebra }\end{array}$ & $\begin{array}{l}\text { Fully/semi- } \\
\text { segmented }\end{array}$ & $\begin{array}{l}\text { United } \\
\text { to }\end{array}$ & $\begin{array}{l}\text { Associated } \\
\text { intraspinal } \\
\text { anomalies }\end{array}$ & $\begin{array}{l}\text { Risser } \\
\text { sign at } \\
\text { surgery }\end{array}$ & $\begin{array}{l}\text { Risser } \\
\text { sign at } \\
\text { last } \\
\text { follow- } \\
\text { up }\end{array}$ & $\begin{array}{l}\text { Fusion } \\
\text { segments }\end{array}$ & $\begin{array}{l}\text { Operation } \\
\text { time (min) }\end{array}$ & $\begin{array}{l}\text { Blood } \\
\text { loss } \\
(\mathrm{ml})\end{array}$ & Cage & $\begin{array}{l}\text { Follow- } \\
\text { up } \\
\text { (month) }\end{array}$ \\
\hline 1 & $M$ & 11 & L5-S1 & Fully & - & - & 0 & 5 & 3 & 210 & 290 & - & 156 \\
\hline 2 & $F$ & 4 & L5-S1 & Semi & L5 & - & 0 & 5 & 2 & 200 & 300 & - & 132 \\
\hline 3 & M & 9 & L5 & Fully & - & - & 0 & 5 & 4 & 230 & 320 & - & 72 \\
\hline 4 & $M$ & 10 & L5-S1 & Semi & L5 & - & 0 & 5 & 2 & 210 & 300 & - & 120 \\
\hline 5 & M & 12 & L5 & Fully & - & - & 0 & 5 & 3 & 195 & 280 & - & 96 \\
\hline 6 & $F$ & 8 & L5 & Fully & - & - & 0 & 5 & 3 & 200 & 300 & - & 96 \\
\hline 7 & $M$ & 13 & L5-S1 & Semi & L4 & - & 1 & 5 & 3 & 210 & 300 & - & 96 \\
\hline 8 & M & 9 & L5-S1 & Semi & L5 & - & 0 & 4 & 3 & 200 & 270 & - & 66 \\
\hline 9 & $M$ & 6 & L5-S1 & Fully & - & - & 0 & 1 & 3 & 195 & 250 & - & 60 \\
\hline 10 & M & 3 & L5-S1 & Semi & L5 & - & 0 & 5 & 3 & 180 & 280 & - & 132 \\
\hline 11 & $\mathrm{~F}$ & 11 & L5 & Semi & L4 & - & 0 & 5 & 4 & 200 & 320 & - & 60 \\
\hline 12 & $M$ & 11 & L5-S1 & Semi & L5 & - & 0 & 5 & 4 & 210 & 300 & - & 72 \\
\hline 13 & M & 4 & L5 & Semi & L4 & - & 0 & 5 & 2 & 185 & 250 & - & 120 \\
\hline 14 & $F$ & 7 & L5 & Semi & L4 & - & 0 & 4 & 4 & 200 & 250 & - & 72 \\
\hline 15 & M & 3 & L5 & Fully & - & - & 0 & 0 & 4 & 200 & 300 & - & 96 \\
\hline 16 & $F$ & 3 & L5 & Fully & - & $\begin{array}{l}\text { Tethered } \\
\text { cord, syringomyelia }\end{array}$ & 0 & 0 & 3 & 180 & 270 & - & 60 \\
\hline 17 & $F$ & 4 & L6-S1 & Semi & L6 & - & 0 & 1 & 3 & 185 & 290 & - & 96 \\
\hline 18 & $M$ & 12 & L5-S1 & Fully & - & - & 0 & 5 & 3 & 180 & 250 & - & 92 \\
\hline 19 & $F$ & 5 & L6-S1 & Fully & - & - & 0 & 4 & 2 & 200 & 230 & - & 104 \\
\hline 20 & $\mathrm{~F}$ & 6 & L5-S1 & Fully & - & - & 0 & 0 & 2 & 180 & 220 & - & 60 \\
\hline 21 & $M$ & 13 & L5 & Semi & $\llcorner 4$ & - & 1 & 5 & 3 & 210 & 250 & Cage & 60 \\
\hline 22 & $\mathrm{~F}$ & 10 & L5-S1 & Semi & L5 & - & 0 & 5 & 3 & 190 & 230 & - & 60 \\
\hline 23 & $M$ & 5 & L5 & Fully & - & - & 0 & 0 & 2 & 175 & 200 & Cage & 60 \\
\hline
\end{tabular}


Table 2 Comparisons of the coronal and sagittal parameters between pre-operation and postoperation

\begin{tabular}{|c|c|c|c|c|c|c|c|c|c|c|}
\hline & Pre-op & Post-op & $\begin{array}{l}\text { Correction } \\
\text { rate }(\%)\end{array}$ & $\begin{array}{l}P \text { value } \\
\text { (pre-op vs. } \\
\text { post-op) }\end{array}$ & $\begin{array}{l}2 \text { years } \\
\text { post-op }\end{array}$ & $\begin{array}{l}\text { Correction } \\
\text { rate }(\%)\end{array}$ & $\begin{array}{l}P \text { value } \\
\text { (post-op vs. } \\
2 \text { years } \\
\text { post-op) }\end{array}$ & $\begin{array}{l}\text { Last } \\
\text { follow-up }\end{array}$ & $\begin{array}{l}\text { Correction } \\
\text { rate }(\%)\end{array}$ & $\begin{array}{l}P \text { value (post-op } \\
\text { vs. last follow-up) }\end{array}$ \\
\hline \multicolumn{11}{|l|}{ Coronal plane } \\
\hline $\begin{array}{l}\text { Lumbosacral } \\
\text { curve }\left(^{\circ}\right)\end{array}$ & $30.7 \pm 10.4$ & $6.7 \pm 7.1$ & $\begin{array}{l}79.1 \pm \\
19.4\end{array}$ & $<0.001$ & $7.3 \pm 6.1$ & $\begin{array}{l}76.9 \pm \\
17.2\end{array}$ & 0.185 & $8.1 \pm 7.0$ & $73.3 \pm 23.0$ & 0.119 \\
\hline $\begin{array}{l}\text { Compensatory } \\
\text { curve }\left(^{\circ}\right)\end{array}$ & $23.7 \pm 9.4$ & $8.3 \pm 5.2$ & $\begin{array}{l}64.2 \pm \\
21.3\end{array}$ & $<0.001$ & $9.0 \pm 4.8$ & $\begin{array}{l}59.7 \pm \\
23.2\end{array}$ & 0.439 & $9.6 \pm 6.4$ & $60.1 \pm 24.4$ & 0.228 \\
\hline UIV tilt $\left(^{\circ}\right)$ & $15.3 \pm 6.4$ & $3.8 \pm 4.3$ & $\begin{array}{l}73.1 \pm \\
28.1\end{array}$ & $<0.001$ & $4.0 \pm 5.5$ & $\begin{array}{l}73.7 \pm \\
30.6\end{array}$ & 0.583 & $4.6 \pm 6.7$ & $70.3 \pm 35.0$ & 0.145 \\
\hline $\begin{array}{l}\text { Trunk shift } \\
(\mathrm{mm})\end{array}$ & $27.3 \pm 8.6$ & $11.7 \pm 9.4$ & $\begin{array}{l}54.4 \pm \\
35.8\end{array}$ & $<0.001$ & $10.8 \pm 8.2$ & $\begin{array}{l}57.9 \pm \\
31.6\end{array}$ & 0.219 & $10.4 \pm 8.8$ & $60.1 \pm 31.4$ & 0.360 \\
\hline \multicolumn{11}{|l|}{ Sagittal plane } \\
\hline $\begin{array}{l}\text { Lumbosacral } \\
\text { lordosis }\left({ }^{\circ}\right)\end{array}$ & $16.4 \pm 10.1$ & $15.2 \pm 7.0$ & - & 0.475 & $16.2 \pm 7.0$ & - & 0.152 & $15.9 \pm 7.3$ & - & 0.484 \\
\hline $\begin{array}{l}\text { Lumbar } \\
\text { lordosis }\left({ }^{\circ}\right)\end{array}$ & $36.7 \pm 13.4$ & $35.9 \pm 8.6$ & - & 0.726 & $36.9 \pm 6.5$ & - & 0.464 & $38.8 \pm 10.5$ & - & 0.185 \\
\hline $\begin{array}{l}\text { Thoracic } \\
\text { kyphosis }\left(^{\circ}\right)\end{array}$ & $17.7 \pm 10.3$ & $17.6 \pm 6.8$ & - & 0.984 & $18.1 \pm 4.8$ & - & 0.622 & $16.7 \pm 6.0$ & - & 0.567 \\
\hline SVA (mm) & $\begin{array}{l}- \\
5.5 \pm 15.0\end{array}$ & $\frac{-}{9.2} \pm 26.1$ & - & 0.526 & $\begin{array}{l}- \\
5.8 \pm 20.7\end{array}$ & - & 0.225 & $\overline{8.5} \pm 22.5$ & - & 0.855 \\
\hline
\end{tabular}

instrumentation breakage, or pseudoarthrosis was observed during the long-term follow-up. Another patient encountered S1 screw loosening on the right side at the 1-year follow-up and eventually received revision surgery.

\section{Discussion}

The natural history of CS has been well documented in previous studies $[1,2]$. The severity of deformity greatly depends on the type and location of the hemivertebra, and curve progression is usually unavoidable for a fully segmented or semi-segmented hemivertebra $[1,2]$. Because of the lack of motile and compensatory capacity below the sacrum, hemivertebrae located in the lumbosacral region might frequently lead to significant coronal trunk shift and a long proximal compensatory curve at an early age [1-4]. In addition, conservative treatment, including bracing and traction, has been shown to be ineffective [3, 4]. Therefore, early surgical intervention should be recommended for patients with rapid curve progression and significant trunk imbalance $[1-7,12$, 13].

Recently, one-stage posterior-only hemivertebra resection with short segmental instrumentation has become a popular treatment for young patients with LSHV due to the intrinsic benefit of preserving spinal growth and

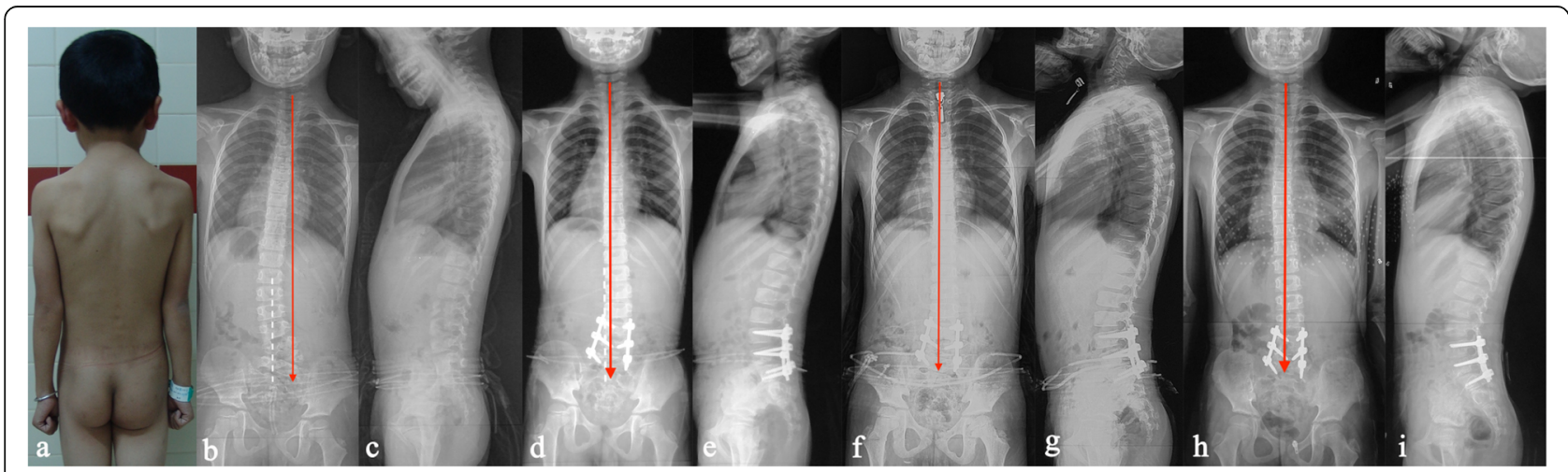

Fig. 2 a-c A 6-year-old boy was identified with a lumbosacral hemivertebra located at L5-S1. The patient presented with a long proximal compensatory curve and significant coronal imbalance. $\mathbf{d}$, e Postoperative radiographs showed excellent correction of both the local and compensatory curves and coronal imbalance. $\mathbf{f}, \mathbf{g}$ The correction was well maintained at the 2-year follow-up. $\mathbf{h}$, $\mathbf{i}$ Both the correction of scoliosis and trunk shift were well maintained at the 5-year follow-up 
mobile segments [12, 13]. Zhuang et al. [12] reported that the lumbosacral curve had an $83 \%$ correction immediately after surgery and an $87 \%$ correction at the last follow-up. In another study by Li et al. [13], the correction rate was $65.5 \%$ immediately after surgery and $55.2 \%$ at the last follow-up. Consistent with the aforementioned studies [7, 12, 13], our results showed that the primary lumbosacral curve had a $79.1 \%$ correction immediately after surgery and a $76.9 \%$ correction at the 2 year follow-up. Additionally, the long-term outcomes demonstrated that posterior-only hemivertebra resection with short segmental fusion is an effective surgical procedure for young patients with LSHV.

Previous studies have confirmed that young age is a potential risk factor for curve progression $[1,2]$. For skeletally immature patients receiving LSHV resection and short fusion, the evolution of the unfused proximal compensatory curve and coronal imbalance are the two major concerns. However, there has been a paucity of studies focusing on the evolution of the compensatory curve during long-term follow-up periods. Our results showed a $64.2 \%$ spontaneous correction of the proximal compensatory curve and a $54.4 \%$ correction of trunk shift immediately after surgery. In addition, with a minimum of 5 years of follow-up, $73.9 \%$ of patients reached or approached skeletal maturity (Risser grade 4 or 5 ). At the last follow-up, the compensatory curve displayed a $60.1 \%$ correction, and trunk shift displayed a $60.1 \% \mathrm{im}$ provement, suggesting the long-term efficacy of the surgical technique.

The relationship between postoperative UIV tilt and surgical outcomes has been explored in scoliosis patients receiving correction surgery $[14,15]$. Liu et al. [14] reported that UIV tilt was correlated with postoperative coronal imbalance in adolescent idiopathic scoliosis patients with Lenke $5 \mathrm{C}$ type curves. In adult degenerative scoliosis patients, Bao et al. [15] also found that patients with unsatisfactory postoperative lumbosacral horizontalization were at high risk of coronal imbalance. Similarly, in CS patients with LSHV, our study also showed that the improvement in trunk shift was significantly correlated with the correction of the UIV tilt, emphasizing the importance of a horizontal lumbosacral foundation for the restoration of coronal balance.

Failure to horizontalize UIV may be attributed to incomplete removal of the hemivertebrae or insufficient resection of the contralateral facet joint or disc. Incomplete removal of hemivertebrae may hamper convex compression. Moreover, the growth of the residual part of the hemivertebra may cause the lumbar "take-off" phenomenon and subsequent coronal imbalance, as demonstrated by Nakamura et al. [10]. In addition, the concave facet joint and disc should also be resected sufficiently to provide a circumferential release for the restoration of lumbosacral horizontalization. In patients with a large cavity after excision of a large hemivertebra, it may be difficult to completely achieve "bone to bone" closing via a simple compression maneuver. Therefore, a cage filled with a cancellous autograft may be used when necessary.

The neurologic complications of hemivertebra resection via the posterior approach have been well documented in previous studies $[7,13,16,17]$. Bollini et al. [7] reported a tibialis motor deficit with incomplete recovery in a patient undergoing LSHV resection. Li et al. [13] noted that three patients encountered transient neurological complications after posterior-only LSHV resection. In our study, one patient with a semisegmented hemivertebra located at L5-S1 was noted with transient right foot weakness after surgery, possibly due to the stretching of the nerve root. The patient recovered completely 3 months later. Hence, despite the high demand for this technique, LSHV resection via the posterior-only approach seems to be a safe procedure.

Implant-related failure is another major complication for young patients. Lyu et al. [18] reported two patients with implant failure in 17 CS patients with lumbosacral fixation. In the study by Ruf et al. [19], implant failure occurred in $7.3 \%(3 / 41)$ of patients. In our study, one patient was demonstrated to have screw loosening at the 1-year follow-up. Most patients with implant-related failures require revision surgery. The causes for this complication are manifold and include young age, limited implant, and short fusion [20]. Therefore, for young patients who undergo LSHV resection and short segmental fusion, immobilization via a brace for at least 3 months is indispensable.

To the best of our knowledge, this is the first study presenting the evolution of scoliosis and coronal imbalance with a long-term follow-up. Another highlight is that the homogeneous nature of this cohort, which excluded patients with multiple hemivertebrae, made our results more convincing. Despite the relatively small sample size, however, this study included the largest cohort to date. Furthermore, considering the harmfulness of excessive radiation exposure, a postoperative $\mathrm{CT}$ scan was not routinely performed in our study. Inevitably, another intrinsic weakness of this study is its retrospective nature. Additionally, the clinical outcomes were not assessed due to the relatively young age of the included cohort.

\section{Conclusions}

For patients with CS due to LSHV, one-stage posterioronly hemivertebra resection and short segmental fusion can provide excellent scoliosis correction and trunk shift improvement. In addition, the restoration of lumbosacral horizontalization should be given great attention during surgery. 


\section{Abbreviations}

CS: Congenital scoliosis; CSVL: Central sacral vertical line; CT: Computed tomography; LSHV: Lumbosacral hemivertebra; MEP: Motor evoked potential; MRI: Magnetic resonance imaging; SEP: Sensory evoked potential;

SVA: Sagittal vertical axis; UIV: Upper instrumented vertebra

\section{Acknowledgements}

None.

\section{Authors' contributions}

YQ and YW conceived and designed the study. ZL, CZD, and BLS collected the data. XS and BW performed the statistical analysis. YW and ZZZ wrote the manuscript. All authors read and approved the final manuscript.

\section{Funding}

This research was supported by the Jiangsu Health and Family Planning Commission (Grant Q201510) and Nature Science Foundation of Jiangsu Province (Grant BK20171116).

\section{Availability of data and materials}

Please contact author for data requests.

\section{Ethics approval and consent to participate}

This study was approved by the ethics committee of Nanjing Drum Tower Hospital affiliated to Medical School of Nanjing University.

\section{Consent for publication}

All the patients in this study have given their informed consent for the article to be published.

\section{Competing interests}

The authors declare that they have no competing interests.

\section{Author details}

${ }^{1}$ Department of Spine Surgery, Nanjing Drum Tower Hospital, Clinical College of Nanjing Medical University, Zhongshan Road 321, Nanjing 210008 China. ${ }^{2}$ Department of Spine Surgery, Nanjing Drum Tower Hospital, Medical School of Nanjing University, Zhongshan Road 321, Nanjing 210008, China.

Received: 12 June 2019 Accepted: 22 November 2019

Published online: 11 December 2019

\section{References}

1. McMaster MJ, Ohtsuka K. The natural history of congenital scoliosis. A study of two hundred and fifty-one patients. J Bone Joint Surg Am. 1982;64:1128-47.

2. McMaster MJ, David CV. Hemivertebra as a cause of scoliosis. A study of 104 patients. The Journal of bone and joint surgery. British volume 1986;68:588595.

3. Slabaugh PB, Winter RB, Lonstein JE, et al. Lumbosacral hemivertebrae. A review of twenty-four patients, with excision in eight. Spine (Phila Pa 1976). 1980:5:234-44.

4. Leong JC, Day GA, Luk KD, et al. Nine-year mean follow-up of one-stage anteroposterior excision of hemivertebrae in the lumbosacral spine. Spine (Phila Pa 1976). 1993;18:2069-74.

5. Yaszay B, O'Brien M, Shufflebarger HL, et al. Efficacy of hemivertebra resection for congenital scoliosis: a multicenter retrospective comparison of three surgical techniques. Spine (Phila Pa 1976). 2011:36:2052-60.

6. Holte DC, Winter RB, Lonstein JE, et al. Excision of hemivertebrae and wedge resection in the treatment of congenital scoliosis. J Bone Joint Surg Am. 1995;77:159-71.

7. Bollini G, Docquier PL, Viehweger E, et al. Lumbosacral hemivertebrae resection by combined approach: medium- and long-term follow-up. Spine. 2006;31:1232-9

8. Zhu F, Sun X, Qiao J, et al. Misplacement pattern of pedicle screws in pediatric patients with spinal deformity: a computed tomography study. J Spinal Disord Tech. 2014:27:431-5.

9. Ruf M, Harms J. Posterior hemivertebra resection with transpedicular instrumentation: early correction in children aged 1 to 6 years. Spine (Phila Pa 1976). 2003;28:2132-8.
10. Nakamura $H$, Matsuda $H$, Konishi $\mathrm{S}$, et al. Single-stage excision of hemivertebrae via the posterior approach alone for congenital spine deformity: follow-up period longer than ten years. Spine (Phila Pa 1976) 2002:27:110-5.

11. Crostelli M, Mazza O, Mariani M. Posterior approach lumbar and thoracolumbar hemivertebra resection in congenital scoliosis in children under 10 years of age: results with 3 years mean follow up. Eur Spine J. 2014:23:209-15.

12. Zhuang Q, Zhang J, Li S, et al. One-stage posterior-only lumbosacral hemivertebra resection with short segmental fusion: a more than 2-year follow-up. Eur Spine J. 2016;25:1567-74.

13. Li Y, Wang G, Jiang Z, et al. One-stage posterior excision of lumbosacral hemivertebrae. Medicine. 2017:96:e8393.

14. Liu Z, Guo J, Zhu Z, et al. Role of the upper and lowest instrumented vertebrae in predicting the postoperative coronal balance in Lenke $5 \mathrm{C}$ patients after selective posterior fusion. Eur Spine J. 2013;22:2392-8.

15. Bao H, Yan P, Qiu Y, et al. Coronal imbalance in degenerative lumbar scoliosis: Prevalence and influence on surgical decision-making for spinal osteotomy. Bone Joint J. 2016;98-b:1227-33.

16. Lazar RD, Hall JE. Simultaneous anterior and posterior hemivertebra excision. Clin Orthop Relat Res. 1999;364:76-84.

17. Hedequist DJ, Hall JE, Emans JB. Hemivertebra excision in children via simultaneous anterior and posterior exposures. J Pediatr Orthop. 2005;25: 60-3.

18. Lyu Q, Hu B, Zhou C, et al. The efficacy of posterior hemivertebra resection with lumbosacral fixation and fusion in the treatment of congenital scoliosis: a more than 2-year follow-up study. Clin Neurol Neurosurg. 2018; 164:154-9.

19. Ruf $M$, Jensen $R$, Letko $L$, et al. Hemivertebra resection and osteotomies in congenital spine deformity. Spine (Phila Pa 1976). 2009;34:1791-9.

20. Guo J, Zhang J, Wang S, et al. Risk factors for construct/implant related complications following primary posterior hemivertebra resection: study on 116 cases with more than 2 years' follow-up in one medical center. BMC Musculoskelet Disord. 2016;17:380.

\section{Publisher's Note}

Springer Nature remains neutral with regard to jurisdictional claims in published maps and institutional affiliations.
Ready to submit your research? Choose BMC and benefit from:

- fast, convenient online submission

- thorough peer review by experienced researchers in your field

- rapid publication on acceptance

- support for research data, including large and complex data types

- gold Open Access which fosters wider collaboration and increased citations

- maximum visibility for your research: over $100 \mathrm{M}$ website views per year

At BMC, research is always in progress.

Learn more biomedcentral.com/submissions 